EDITORIAL

\title{
Magnetic Resonance in Poland
}

\author{
Maria Jerzykiewicz ${ }^{1} \cdot J^{\prime} u l i a$ Jezierska ${ }^{1} \cdot$ Szymon Łoś $^{2}$
}

Published online: 3 May 2019

(c) Springer-Verlag GmbH Austria, part of Springer Nature 2019

The Polish EMR Group brings together researchers who use EPR spectroscopy as the leading method. The directions of their research are very diverse and only some of them have been presented in this Special Issue of Applied Magnetic Resonance: Magnetic Resonance in Poland. We hope that even the publications that are included in this issue will show that members of the Polish EMR group conduct a wide range of research from purely theoretical to environmental ones, which concern such diverse materials as alloys, graphene, doped crystals and soils.

We would like to thank in particular the Editor-in-chief of Applied Magnetic Resonance, Professor Kev M. Salikhov and his editorial team, especially Dr. Laila Mosina, for the kind acceptance of our proposal to publish this special issue and invaluable help in its preparation.

Publisher's Note Springer Nature remains neutral with regard to jurisdictional claims in published maps and institutional affiliations.

Maria Jerzykiewicz

maria.jerzykiewicz@chem.uni.wroc.pl

Julia Jezierska

julia.jezierska@chem.uni.wroc.pl

Szymon Łoś

szymon@ifmpan.poznan.pl

1 Wrocław University, Wrocław, Poland

2 Institute of Molecular Physics, Polish Academy of Sciences, Poznań, Poland 